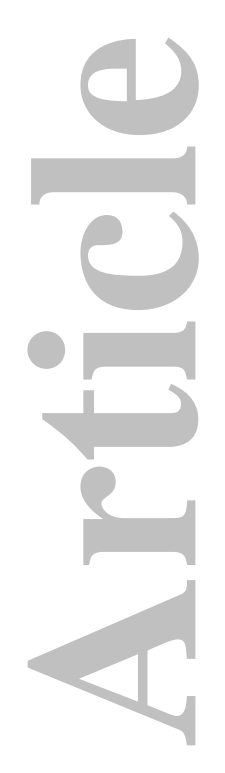

SCHOLARONE $^{\mathrm{s}}$
Manuscripts

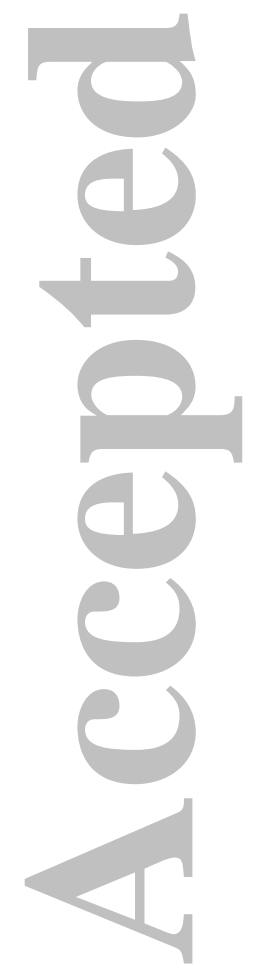

This is the author manuscript accepted for publication and has undergone full peer review but has not been through the copyediting, typesetting, pagination and proofreading process, which may lead to differences between this version and the Version record. Please cite this article as doi:10.1002/ hed.24872. 


\section{Clinical outcomes after local field conformal reirradiation of patients with retropharyngeal nodal metastasis}

Courtney Pollard III, MD, PhD ${ }^{1}$, Theresa P. Nguyen, BS ${ }^{1}$, Sweet Ping Ng, MBBS ${ }^{1}$, Steven J. Frank, $\mathrm{MD}^{1}$, Adam S. Garden, $\mathrm{MD}^{1}$, Gary B. Gunn, $\mathrm{MD}^{1}$, Clifton D. Fuller, MD, PhD ${ }^{1}$, Beth M. Beadle, $\mathrm{MD}, \mathrm{PhD}^{5}$, William H. Morrison, $\mathrm{MD}^{1}$, Shah J. Shah, $\mathrm{MD}^{1}$, He Wang, PhD ${ }^{2}$, Sam Tung, PhD ${ }^{2}$, Conjun Wang, $\mathrm{PhD}^{2}$, Lawrence D. Ginsberg, $\mathrm{MD}^{3}$, Mark E. Zafereo, MD ${ }^{4}$, Erich M. Sturgis, $\mathrm{MD}^{4}$, Shirley Y. Su, MBBS ${ }^{4}$, Ehab Y. Hanna, MD ${ }^{4}$, David I. Rosenthal, MD ${ }^{1}$, Jack Phan, MD, PhD ${ }^{1, *}$

${ }^{1}$ Department of Radiation Oncology, University of Texas MD Anderson Cancer Center, Houston, TX, USA

${ }^{2}$ Department of Radiation Physics, University of Texas MD Anderson Cancer Center, Houston, TX, USA

${ }^{3}$ Department of Diagnostic Radiology, University of Texas MD Anderson Cancer Center, Houston, TX, USA

${ }^{4}$ Department of Head and Neck Surgery, University of Texas MD Anderson Cancer Center, Houston, TX, USA

${ }^{5}$ Department of Radiation Oncology, Stanford University, Stanford, CA, USA

${ }^{*}$ Corresponding Author

Short Title: Reirradiation in setting of retropharyngeal node metastasis

Classification: Original Article

Manuscript information: Total Word Count: (4499), Word count (not including title page, abstract, figure legends, references): (3155), Abstract word count: (147), Reference number: (32), Figures: 4, Tables: 2. Text pages: 19.

*Corresponding Author: Jack Phan, Department of Radiation Oncology, MD Anderson Cancer Center, Gimbel (B2.4863) 1515 Holcombe Blvd, Unit 0097, Houston, Texas, 77030. Phone: (713) 792-5373. Fax: (713)563-2366. e-mail: jphan@mdanderson.org

Acknowledgements: We would like to acknowledge the University of Texas MD Anderson Cancer Center for designating Jack Phan, M.D., Ph.D., as a Hearst Clinical Innovator Awardee.

Keywords: retropharyngeal, reirradiation, conformal radiotherapy, recurrent, stereotactic body radiation therapy

Meetings: Presented in poster format at 2016 American Society of Therapeutic Radiation Oncology (ASTRO) annual meeting, Boston, MA. Presented as oral presentation at 2017 Texas Radiological Society (TRS) 2017 annual meeting, Galveston, TX. Presented in poster format at 2017 American Head and Neck Society (AHNS) annual meeting, San Diego, CA. 


\section{Abstract}

Background. We present our experience with retropharyngeal node reirradiation using highly conformal radiotherapy.

Methods. A retrospective screen of 2504 consecutively irradiated patients with head and neck malignancies between $2005-2015$ identified 19 patients that underwent reirradiation for retropharyngeal node metastasis. Clinical and toxicity outcomes were assessed in these patients.

Results. Thirteen (68\%) patients had squamous cell carcinoma. Eleven (58\%) received conventionally fractionated intensity modulated radiotherapy (IMRT) or proton therapy, and eight (42\%) received single- or hypo-fractionated stereotactic radiotherapy. Fourteen (74\%) received chemotherapy. Median follow up was 14.7 months. The 1-year local control, locoregional control, overall survival, and progression free survival rates were 100\%, 94\%, 92\%, $92 \%$, respectively. Three patients (16\%) experienced acute grade 3 toxicity and occurred in those treated with IMRT. There was no late grade $\geq 3$ toxicity.

Conclusions. Retropharyngeal node reirradiation with conformal therapy is well tolerated and associated with excellent short-term disease control. 


\section{Introduction}

Retropharyngeal (RP) lymph nodes are located in the buccopharyngeal fascia, posterior to the superior portion of the nasopharynx, and anterior to the arch of atlas. The RP lymph nodes directly drain the nasal cavity, nasopharynx, and the auditory tubes. The node of Rouviere is the most superior of the lateral group of RP nodes, can be involved in cancers of the nasopharynx, oropharynx, hypopharynx, and paranasal sinus, and metastasis to this location is a harbinger of poor prognosis ${ }^{1}$.

Radiation therapy is often used to target RP nodes as definitive treatment for gross disease involvement or as a prophylactic measure in head and neck (HN) sites with predilection for RP nodal metastases. Elective irradiation to RP nodal basins in patients with high-risk primary sites result in exceptional locoregional control ${ }^{2}$. Intensity modulated radiation therapy (IMRT) allows for the use of a simultaneous integrated boost technique with more selective and precise dose delivery to different organs and requires delineation of RP nodes as a clinical target. At our institution prophylactic doses of 54-57 Gy to the RP nodal basins (in the absence of gross involvement) are typically considered in patients with malignancies of the pharynx.

Patients with RP recurrences after radiation therapy can be salvaged by surgical resection. However, due to proximity of critical structures such as the carotid artery and prevertebral fascia, complete resection of tumor may be associated with a high risk of morbidity. RP node reirradiation is a potentially curative strategy and newer conformal techniques offer the potential of reduced toxicity. Currently, there is sparse clinical data on RP reirradiation outcomes making it difficult to decipher optimal management for these patients ${ }^{3}$. Studies including reirradiation of RP nodes are analyzed in aggregate with other head and neck 
sites and the numbers are small. In this study we present our single institutional experience treating recurrent RP node disease with local field radiation therapy utilizing IMRT, proton beam therapy (PBT), head and neck stereotactic body radiation therapy (HN-SBRT), and gamma knife stereotactic radiosurgery (GK-SRS), evaluating clinical outcomes and treatment related toxicity.

\section{Methods and Materials}

\section{Patients}

This study was approved by the institutional review board and informed consent obtained from study participants. We queried the medical records of all patients from 2000 to early-2015 in our departmental database. Of the 2504 patients with HN malignancies previously irradiated from 2000 to early-2015, we identified a total of 26 patients that ultimately developed recurrences in the RP node basin and subsequently received reirradiation with curative intent. Of these, 6 patients were excluded for having multifocal recurrent disease including those with involvement of the oropharynx $(n=3)$, nasal cavity $(n=1)$ and skull base $(n=2)$. One patient was excluded due to not completing the intended treatment. Patients with $<2 \mathrm{~cm}$ direct extension to the adjacent nasopharynx or ipsilateral neck $(n=5)$ were included.

Of the 19 patients, human papilloma virus (HPV)-status was available in only 4 samples (1 HPV positive) and therefore was not factored in further analyses. RP node recurrences were verified by biopsy and/or radiographic imaging. Diagnostic imaging obtained included magnetic resonance imaging (MRI), positron emission tomography-computed tomography (PET-CT), and/or computed tomography (CT). 
After reirradiation, follow-up evaluations were performed at 3 months interval during the first year post-treatment, at 4 months interval between years 1 and 2 post-treatment, at 6 months interval between years 2 and 5 post-treatment, and annually thereafter according to institutional guidelines after reirradiation. As of 2013, these guidelines were formalized as part of our reirradiation protocol. Follow-up evaluation consisted of repeat history, symptom assessment, physical examination and imaging studies. Physical examination included nasopharyngolaryngoscopic exam by a staff radiation oncologist. Imaging studies included MRI, PET-CT scan, and/or CT at the discretion of the treating physician.

\section{Treatment Planning}

IMRT, HN-SBRT and PBT patients received a simulation CT scan with a custom head and neck mask. IMRT/volumetric arc therapy (VMAT) and HN-SBRT treatment plans were performed using the Pinnacle treatment planning system (Philips Healthcare, Fitchburg, WI). For HN-SBRT patients, 1-mm planning CT images were coregistered with planning MRI images, contrast-enhanced CT or PET-CT images in treatment position to delineate target and critical avoidance structures such as carotid vessels (Figure 1A-C). PBT plans were created using the Eclipse proton therapy planning system (Varian Medical Systems, Palo Alto, CA). Gamma Knife treatment plans were performed with the Leksell GammaPlan treatment planning system (Elekta, Stockholm, Sweden). For IMRT and PBT plans, contouring involved identifying the gross tumor volume with an $8-10 \mathrm{~mm}$ circumferential margin designated as clinical target volume 1 (CTV 1). When the target volume abutted critical structures a reduced CTV1 margin was used (0 $-5 \mathrm{~mm})$, which was ultimately determined by the treating radiation oncologist. Intermediate and elective nodal doses were used sparingly and only with IMRT or PBT treatment plans. 
IMRT was either delivered using a step-and-shoot technique or volumetric modulated arc therapy technology. Both techniques utilized multileaf collimation. Planning target volumes (PTVs) were generated by expanding the corresponding CTV by $3 \mathrm{~mm}$. Dose was prescribed to the PTV with the goal of $>95 \%$ coverage.

PBT was delivered using a 2-field or 3-field passive scatter proton therapy or by active scanning intensity modulated proton therapy (IMPT). Beam angles were chosen for each plan to optimize target coverage while minimizing dose to OARs. Final optimization was performed accounting for range and isocenter shift uncertainties as previously reported ${ }^{4}$. We previously published the technical and planning methods of our IMPT experience ${ }^{4-6}$.

HN-SBRT treatment was delivered using the Varian TrueBeam STx system (Varian Medical Systems, Inc., Palo Alto, Ca) with high definition (2.5 mm) leaflets and planned using 23 arc VMAT technique with patients immobilized in a custom biteblock-mask-cushion system with image guided on-line setup correction as previously described ${ }^{7-9}$. HN-SBRT was delivered in 5 fractions every other day over 2 weeks.

GK-SRS was delivered using the Leksell Perfexion (Elekta, Stockholm, Sweden). On the morning of treatment, a rigid head frame was placed on patient under local anesthesia by the neurosurgeon and thin-slice (1-mm) gadolinium-enhanced MRIs (T1 sequence) were performed and then transferred to the Leksell GK treatment planning system for treatment planning.

Treatment volumes (gross tumor with no PTV margin) were prescribed to the $50 \%$ isodose line with a mean dose of $17.5 \mathrm{~Gy}$.

\section{Data Analysis}

John Wiley \& Sons, Inc.

This article is protected by copyright. All rights reserved. 
Endpoints included local control (LC), locoregional control (LRC), progression free survival (PFS), and overall survival (OS) calculated from the end of radiation treatment using the Kaplan-Meier algorithm based on a first event analysis for all endpoints. For the purposes of this analysis, local recurrence was defined as persistence or recurrence in the treated RP disease, and regional recurrence as recurrence in any head and neck site (mucosal or nodal) exclusive of the treated RP nodes. Actuarial statistics for clinical outcomes were calculated using SPSS Statistics v. 23.0 (IBM Corporation, Armonk, NY). Toxicity was determined using the Common Terminology Criteria for Adverse Events (CTCAE v.4.0). Toxicity parameters were assessed at follow up and graded by the treating radiation oncologist.

\section{Results}

\section{Patient and treatment characteristics}

Table 1 summarizes patient, tumor and treatment characteristics. Of the 19 patients that received RP node reirradiation, 14 (74\%) had isolated RP node recurrences, and 5 (26\%) had RP node recurrences with limited direct extension to either the ipsilateral level 2A neck $(n=3)$ or nasopharynx $(n=2)$ (Figure $2 A-C)$. Twelve (63\%) patients were male. Initial primary sites included: tonsil $(n=3)$, oral cavity $(n=3)$, nasopharynx $(n=3)$, nasal cavity $(n=3)$, larynx $(n=2)$, sinonasal $(n=2)$, thyroid $(n=1)$, parotid $(n=1)$, unknown primary $(n=1)$. The majority of patients $(n=13)$ had squamous cell carcinoma (SCC). The non-SCC histologies included: nasopharyngeal carcinoma $(n=3)$, sinonasal undifferentiated carcinoma (SNUC) $(n=1)$, esthesioneuroblastoma $(n=1)$, and medullary thyroid carcinoma $(n=1)$.

The median time interval between first and second radiation courses was 40.2 months (range: 10.3 - 127.9 months). Reirradiation modalities were IMRT ( $n=7)$, HN-SBRT (n=6), PBT ( 
$=4$ ), and single fraction GK-SRS ( $n=2$ ) (Figure 3A - D). Among the 5 patients with limited extension beyond the RP nodal basin, 3 received IMRT and 2 received HN-SBRT. The median dose/fractionation for IMRT, PBT and HN-SBRT were 66Gy/33 fractions, 45Gy/5 fractions delivered every other day, and 68Gy/33 fractions, respectively. The mean single fraction GKSRS dose was 17.5 Gy prescribed to the $50 \%$ isodose line.

Fourteen (74\%) patients received systemic therapy. One patient received induction, 13 received concurrent, and 3 received both induction and concurrent systemic therapy. Concurrent systemic therapy consisted of: cetuximab $(n=7)$, cisplatin $(n=3)$, and carboplatin $(n=3)$. Induction systemic therapy consisted of: carboplatin/etoposide $\times 3$ cycles $(n=1)$, carboplatin/docetaxel x 3 cycles ( $n=2)$, and carboplatin/paclitatel/cetuximab x 6 cycles $(n=1)$.

\section{Clinical Outcomes}

The median follow up time after reirradiation was 14.7 months (range: $3.3-103.9$ months). The 1-year LC, LRC, OS, and PFS rates for the entire patient cohort were $100 \%, 94 \%$, 92\%, and 92\% respectively (Figure 4A - D). There were no local recurrences and 3 regional recurrences: posterior sinonasal cavity $(n=1)$, ipsilateral supraclavicular node $(n=1)$ and contralateral upper neck $(n=1)$ outside of the reirradiation field. The patient with disease recurrence of the posterior sinonasal cavity was treated with GK-SRS for left-sided isolated RP recurrence from history of a multiply recurrent esthesioneuroblastoma status-post surgery and postoperative radiotherapy. This patient developed a recurrence 19.7 months after GK-SRS and was salvaged with HN-SBRT and currently displays no evidence of disease (NED). There was 1 distant recurrence involving the lung. This patient also had a regional recurrence. The median time to recurrence after reirradiation was 19.7 months (range $1.9-23.9$ months). Of the 3 
regional recurrences, 1 was treated with GK-SRS, 1 was treated SBRT, and 1 was treated with IMRT, and two (67\%) did not receive chemotherapy.

\section{Treatment Related Toxicity}

A total of 35 physician reported toxicities events were identified ( 28 acute and 7 late).

There were 3 acute G3 adverse events. There were no G4-5 events reported. All G3 acute adverse events were related to mucositis $(n=3)$ requiring narcotics and interfering with oral intake, and occurred in patients treated with IMRT (43\%; 3 of 7 patients treated with IMRT).

There were no $\geq$ G3 late toxicities. Of the 7 reported G1-2 late toxicities, xerostomia $(n=5)$ was the most common event. One patient developed $G 2$ trismus that was initially treated with 3D-CRT for supraglottic larynx cancer and reirradiated to the left RP node 7 years later with PBT. One patient previously treated with IMRT for nasopharynx cancer in 2001 and reirradiated with IMRT for a left RP recurrence 7 years later, developed mild asymptomatic radiation-induced left temporal lobe necrosis 2 years after reirradiation. Review of the reirradiation plan showed a dose of $20 \mathrm{~Gy}$ in 33 fractions in the area of radionecrosis. The original RT plan was not available. All 7 patients with late toxicities also had acute toxicities. Treatment related toxicity data is summarized in absolute number of reported symptoms in Table 2.

\section{Discussion}

Management of RP node recurrence after prior head and neck radiotherapy represents a therapeutic challenge. Historically, the use of surgery is preferred over reirradiation because of severe toxicity concerns with repeat high dose radiation (cumulative dose $>100 \mathrm{~Gy}$ ) such as 
severe fibrosis, dysphagia, xerostomia, carotid artery rupture, soft tissue necrosis and osteoradionecrosis ${ }^{10}$. Here, we demonstrate that use of highly conformal radiotherapy techniques for reirradiation of RP node recurrences offers excellent disease control with 1-year LC of $100 \%$ and LRC of $94 \%$. Treatment was well tolerated and toxicity was limited to acute mucositis in $16 \%$ of patients. The majority of our patients received chemotherapy in some form, which may account for the favorable disease control.

Several studies have investigated the impact RP nodal metastasis on disease outcomes $^{11-13}$. Gunn et al. found that RP node involvement in patients with oropharyngeal cancer was associated with worse 5-year LC (79\% vs 92\%), nodal control (80\% vs. 93\%), recurrence-free survival (51\% vs. $81 \%)$, and OS (52\% vs. $82 \%)(P<0.001 \text { for all })^{14}$. Dirix et al. demonstrated patients with RP lymphadenopathy at the time of diagnosis had higher rates of regional recurrence $(45 \%$ vs. $10 \%, p=0.004)$ and lower disease specific survival ( $38 \%$ vs. $58 \%, p$ $=0.03)^{15}$. Harada et al. showed that patients with hypopharyngeal cancer and RP nodal involvement had significantly worse 2 -year OS (0\% vs. 68\%, p < 0.01) and 2-year cause specific survival $(0 \%$ vs. $74 \%, p<0.01)$ than those with no RP node involvement ${ }^{16}$.

Although Garden et al. showed that RP node recurrence in electively treated patients is rare $^{17}$, in those who do recur, evidence suggests surgical salvage of RP node metastasis improves tumor control and survival ${ }^{18}$. Depending on the location of the recurrence, surgical resection can be accomplished by a transcervical or transmandibular approach. The maxillary swing operation, an open procedure, has been defined as an effective approach to resect tumor in the RP space because it provides superior surgical access and an ability to resect the parapharyngeal space en bloc with the pharyngobasilar fascia ${ }^{18,20,21}$. However, open surgical 
procedures are associated with multiple morbidities including surgical site infections, cranial nerve palsies, palatal fistula, trismus, cerebrospinal fluid leak, velopharyngeal incompetence, choanal stenosis, dental malocclusion, and poor wound healing related to atrophy of surgically involved soft tissues ${ }^{19,22,23}$. Chan et al. analyzed 82 patients with RP recurrences after definitive radiation therapy for nasopharyngeal carcinoma and subsequently salvaged with the maxillary swing approach ${ }^{18}$. The 5-year actuarial tumor control and overall disease free survival (DFS) of patients were $79.6 \%$ and 59\%, respectively. Quality of life assessment in these patients showed that the most significant side effects were palatal fistula (4.3\%), severe trismus (13.5\%), and osteoradionecrosis $(16.2 \%$, attributed to a combination of primary radiotherapy and exposed bone after surgical procedure $)^{24}$. Endoscopic transnasal surgery and transoral robotic surgery (TORS) are alternatives to open approaches in select cases but require resection of the nasopharynx to expose the parapharyngeal space, which may lead to unnecessary risks of carotid artery damage, middle ear effusion and hearing damage. In patients with isolated RP node recurrences, routine resection of the nasopharynx may incur unnecessary risks.

Highly conformal radiotherapy techniques have reinvigorated a reassessment of curative intent reirradiation as an alternative treatment option for selected patients with $\mathrm{HN}$ cancer $^{25-30}$. However, for those with RP recurrences, the clinical evidence supporting use of reirradiation in the literature is sparse $\mathrm{e}^{25,28,29}$. In the present study, we demonstrated excellent local control after isolated RP node reirradiation with no significant differences among single-, hypo- and conventionally-fractionated approaches, suggesting an adequate biologic effective dose can be achieved with stereotactic radiation therapy using 16-18 Gy in a single fraction or 40-45 Gy in 5 fractions, confirming findings from other head and neck stereotactic radiation 
therapy studies evaluating the optimal dose/fractionation for recurrent head and neck tumors $^{27,30}$.

The incidence of acute grade 3 (G3) toxicities was low ( $11 \%$ of all acute toxicities) with no acute G4-5 toxicities, and late toxicity was limited to G1-2 events. The majority (84\%) of our patients had non-nasopharyngeal cancers and likely received less total radiation dose to the nasopharyngeal/RP region, which may partially account for the lower rates of toxicity in this cohort compared to reported $\mathrm{HN}$ reirradiation rates ${ }^{31,32}$. Our previously reported institutional HN reirradiation data showed 1 - and 2 -year $\geq G 3$ toxicity rates of $19.9 \%$ and $32 \%$ (for IMRT) and $16.5 \%$ and $27.1 \%$ (for PBT), respectively, and that retreatment volume was associated with toxicity rates ${ }^{26,28}$. In patients with CTV1 volumes $<50 \mathrm{cc}$ the 1-year $\mathrm{G} 3$ toxicity rates were significantly lower (11.6\% for IMRT; and $8.7 \%$ for PBT), and similar to toxicity rates presented here. In our current study, all 3 acute $\mathrm{G} 3$ toxicity events were mucositis and occurred in IMRT patients ( $n=7$; representing $43 \%$ of IMRT patients) and none in those who received PBT, HNSBRT, or GK-SRS, suggesting increased conformality and lower integral dose are advantageous in the reirradiation setting.

This study has several limitations, including inherent biases of a retrospective analysis, limited patient number, and a relatively short follow up period. In addition, the patient population includes tumors of different histologies and the use of varying induction and concurrent chemotherapy regimens which can impact clinical outcome. A previous benchmark study by Gunn et al. evaluated a cohort of nearly 1000 patients with oropharyngeal SCC and the incidence of radiographically involved RP node was $\sim 10 \%{ }^{14}$. In our database of 2504 head and neck radiotherapy patients, approximately $1 \%$ (26 patients) were found to have a RP recurrence 
in a previously irradiated field. These findings are consistent with our prior observations that recurrence in electively treated regions is extremely rare ${ }^{17}$ and support our institutional approach of routine elective RP nodal irradiation in patients with pharyngeal and posterior nasal cavity primaries. Physician reported assessment of adverse events can vary in incidence and severity, and parsing out the influence of prior treatment is a challenge. Evaluating G3 or higher toxicities help mitigate some of these concerns. Conversely, the strength of this study is a unique assessment of a homogeneous patient population reirradiated to the RP nodal basins using highly conformal modalities.

\section{Conclusions}

Conformal local field reirradiation in patients with RP nodal recurrences offers excellent local control and survival at 1 year and is well tolerated. The use of limited field reirradiation may provide an alternative to surgical salvage strategies and appears associated with a favorable toxicity profile. Longer-term follow up and greater patient numbers are needed to confirm clinical outcomes and late effects of RP node reirradiation. Due to the rarity of the clinical presentation, a large prospective randomized controlled trial would be difficult to implement.

John Wiley \& Sons, Inc. 


\section{Figure Legend}

Figure 1. Treatment planning procedure for patients treated with HN-SBRT. (A) Representative axial slice of planning CT scan, $1 \mathrm{~mm}$ slice. The right RP tumor and carotid vessels are difficult to visualize. White arrow identifies the right RP tumor. Hollow red circle is isocenter. (B)

Coregistration of the planning CT scan with a volume MRI in treatment immobilization position.

Visualization of the tumor (white arrow) and contralateral carotid vessel (red arrow). Hollow red circle is isocenter. (C) Final HN-SBRT treatment plan with isodose lines. Right carotid artery (outlined in light blue) is receiving < $8 \mathrm{~Gy}$.

Figure 2. Patterns of disease presentation of patients included in analysis. (A) Isolated right retropharyngeal node metastasis, red circle. (B) Retropharyngeal node metastasis with extension to the ipsilateral carotid space and level 2A, dashed line. (C) Retropharyngeal node metastasis with extension to the ipsilateral nasopharynx, dashed circle.

Figure 3. Radiation treatment plan representative images. (A) IMRT plan. (B) PBT plan. (C) HNSBRT plan. (D) GK-SRS plan.

Figure 4. Clinical outcomes. (A) Local control (LC) for entire patient cohort $(n=19)$. (B) Locoregional control (LRC) for entire patient cohort $(n=19)$. (C) Progression free survival (PFS) for entire patient cohort ( $n=19)$. (D) Overall Survival (OS) for entire patient cohort $(n=19)$. Table 1. Patient, tumor, and treatment characteristics. All patient, tumor, and treatment characteristics are reported in absolute numbers. Abbreviations: SCC, squamous cell carcinoma; SNUC, sinonasal undifferentiated carcinoma; IMRT, intensity modulated radiation therapy; HNSBRT, head and neck stereotactic body radiation therapy; PBT, proton beam therapy; GK-SRS, gamma knife stereotactic radiosurgery; Gy, gray; 
Table 2. Complete toxicity data. All adverse events are reported in absolute numbers.

Abbreviations: No., number; IMRT, intensity modulated radiation therapy; HN-SBRT, head and neck stereotactic body radiation therapy; PBT, proton beam therapy; GK-SRS.
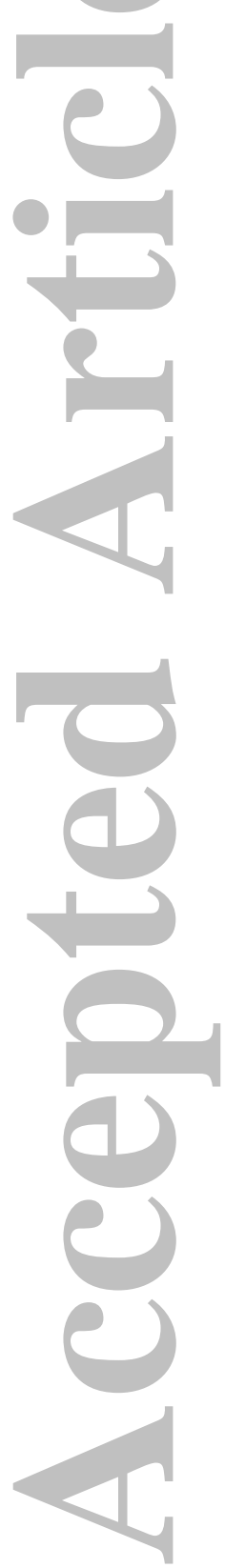

John Wiley \& Sons, Inc.

This article is protected by copyright. All rights reserved. 


\section{References}

1. Coskun HH, Ferlito A, Medina JE, et al. Retropharyngeal lymph node metastases in head and neck malignancies. Head Neck 2011;33:1520-9.

2. Nguyen NP, Vock J, Vinh-Hung V, et al. Effectiveness of prophylactic retropharyngeal lymph node irradiation in patients with locally advanced head and neck cancer. BMC Cancer 2012;12:253.

3. Kawaguchi K, Sato K, Horie A, et al. Stereotactic radiosurgery may contribute to overall survival for patients with recurrent head and neck carcinoma. Radiat Oncol 2010;5:51.

4. Liu W, Frank SJ, Li X, et al. Effectiveness of robust optimization in intensity-modulated proton therapy planning for head and neck cancers. Med Phys 2013;40:051711.

5. Holliday EB, Frank SJ. Proton radiation therapy for head and neck cancer: a review of the clinical experience to date. Int J Radiat Oncol Biol Phys 2014;89:292-302.

6. Quan EM, Liu W, Wu R, et al. Preliminary evaluation of multifield and single-field optimization for the treatment planning of spot-scanning proton therapy of head and neck cancer. Med Phys 2013;40:081709.

7. Pokhrel D, McClinton C, Sood S, et al. Monte Carlo evaluation of tissue heterogeneities corrections in the treatment of head and neck cancer patients using stereotactic radiotherapy. J Appl Clin Med Phys 2016;17:6055.

8. Pokhrel D, Sood S, Badkul R, et al. Assessment of Monte Carlo algorithm for compliance with RTOG 0915 dosimetric criteria in peripheral lung cancer patients treated with stereotactic body radiotherapy. J Appl Clin Med Phys 2016;17:6077.

9. Wang H, Wang C, Tung S, et al. Improved setup and positioning accuracy using a three-point customized cushion/mask/bite-block immobilization system for stereotactic reirradiation of head and neck cancer. J Appl Clin Med Phys 2016;17:6038.

John Wiley \& Sons, Inc.

This article is protected by copyright. All rights reserved. 
10. Patel PR, Salama JK. Reirradiation for recurrent head and neck cancer. Expert Rev Anticancer Ther 2012;12:1177-89.

11. Amatsu M, Mohri M, Kinishi M. Significance of retropharyngeal node dissection at radical surgery for carcinoma of the hypopharynx and cervical esophagus. Laryngoscope 2001;111:1099-103.

12. Gross ND, Ellingson TW, Wax MK, Cohen JI, Andersen PE. Impact of retropharyngeal lymph node metastasis in head and neck squamous cell carcinoma. Arch Otolaryngol Head Neck Surg 2004;130:16973.

13. Hasegawa Y, Matsuura H. Retropharyngeal node dissection in cancer of the oropharynx and hypopharynx. Head Neck 1994;16:173-80.

14. Gunn GB, Debnam JM, Fuller CD, et al. The impact of radiographic retropharyngeal adenopathy in oropharyngeal cancer. Cancer 2013;119:3162-9.

15. Dirix P, Nuyts S, Bussels B, Hermans R, Van den Bogaert W. Prognostic influence of retropharyngeal lymph node metastasis in squamous cell carcinoma of the oropharynx. Int J Radiat Oncol Biol Phys 2006;65:739-44.

16. Harada $R$, Isobe $K$, Watanabe $M$, et al. The incidence and significance of retropharyngeal lymph node metastases in hypopharyngeal cancer. Jpn J Clin Oncol 2012;42:794-9.

17. Garden AS, Morrison WH, Wong PF, et al. Disease-control rates following intensity-modulated radiation therapy for small primary oropharyngeal carcinoma. Int J Radiat Oncol Biol Phys 2007;67:43844.

18. Chan JY, Chow VL, Wong ST, Wei WI. Surgical salvage for recurrent retropharyngeal lymph node metastasis in nasopharyngeal carcinoma. Head Neck 2013;35:1726-31.

19. King WW, Ku PK, Mok CO, Teo PM. Nasopharyngectomy in the treatment of recurrent nasopharyngeal carcinoma: a twelve-year experience. Head Neck 2000;22:215-22.

20. Chan JY. Surgical salvage of recurrent nasopharyngeal carcinoma. Curr Oncol Rep 2015;17:433.

John Wiley \& Sons, Inc.

This article is protected by copyright. All rights reserved. 
21. Chan JY-W, Wong STS, Wei WI. The role of elective neck dissection during surgical salvage for recurrent nasopharyngeal carcinoma. J Nasopharyng Carcinoma 2014;1.

22. Ma QD, Grimm K, Paz BI, Maghami E. Transoral Surgical Approach for Retropharyngeal Node Involvement in I-131-Negative 18-fluoro-2-deoxyglucose Positron Emission Tomography-Positive Recurrent Thyroid Cancer. Skull Base 2009;19:431-6.

23. Shuman AG, Shah JP. Maxillary swing approach for removal of recurrent nasopharyngeal carcinoma. Operative Techniques in Otolaryngology-Head and Neck Surgery 2014;25:248-53.

24. Chan YW, Chow VL, Wei WI. Quality of life of patients after salvage nasopharyngectomy for recurrent nasopharyngeal carcinoma. Cancer 2012;118:3710-8.

25. Chua DT, Sham JS, Kwong PW, Hung KN, Leung LH. Linear accelerator-based stereotactic radiosurgery for limited, locally persistent, and recurrent nasopharyngeal carcinoma: efficacy and complications. Int J Radiat Oncol Biol Phys 2003;56:177-83.

26. Phan J, Sio TT, Nguyen TP, et al. Reirradiation of Head and Neck Cancers With Proton Therapy: Outcomes and Analyses. Int J Radiat Oncol Biol Phys 2016;96:30-41.

27. Rubio C, Morera R, Hernando O, Leroy T, Lartigau SE. Extracranial stereotactic body radiotherapy. Review of main SBRT features and indications in primary tumors. Rep Pract Oncol Radiother 2013;18:387-96.

28. Takiar V, Garden AS, Ma D, et al. Reirradiation of Head and Neck Cancers With Intensity Modulated Radiation Therapy: Outcomes and Analyses. Int J Radiat Oncol Biol Phys 2016;95:1117-31. 29. Teo PM, Kwan WH, Chan AT, Lee WY, King WW, Mok CO. How successful is high-dose $(>$ or $=60$ Gy) reirradiation using mainly external beams in salvaging local failures of nasopharyngeal carcinoma? Int J Radiat Oncol Biol Phys 1998;40:897-913.

30. Vargo JA, Wegner RE, Heron DE, et al. Stereotactic body radiation therapy for locally recurrent, previously irradiated nonsquamous cell cancers of the head and neck. Head Neck 2012;34:1153-61.

John Wiley \& Sons, Inc.

This article is protected by copyright. All rights reserved. 
31. Leung TW, Tung SY, Sze WK, et al. Salvage radiation therapy for locally recurrent nasopharyngeal carcinoma. Int J Radiat Oncol Biol Phys 2000;48:1331-8.

32. Wu SX, Chua DT, Deng ML, et al. Outcome of fractionated stereotactic radiotherapy for 90 patients with locally persistent and recurrent nasopharyngeal carcinoma. Int J Radiat Oncol Biol Phys 2007;69:761-9.
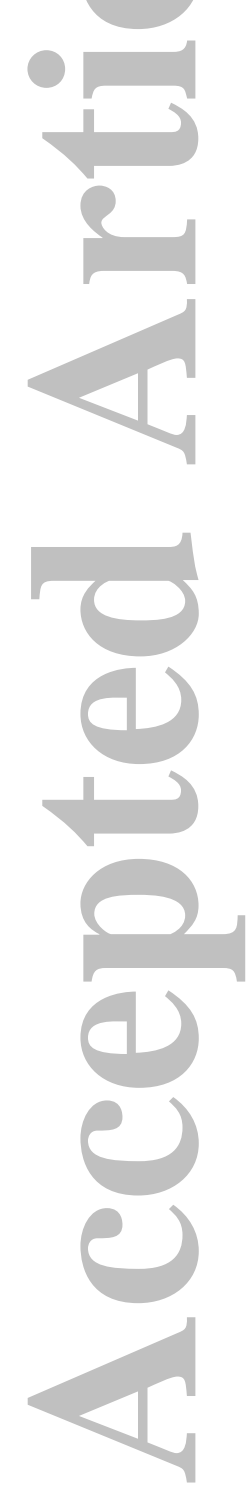

John Wiley \& Sons, Inc.

This article is protected by copyright. All rights reserved. 
A

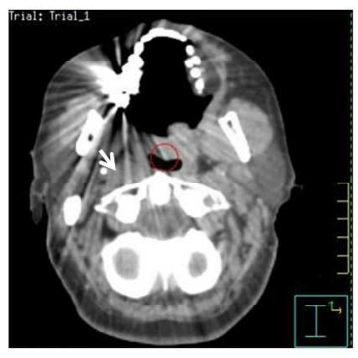

B

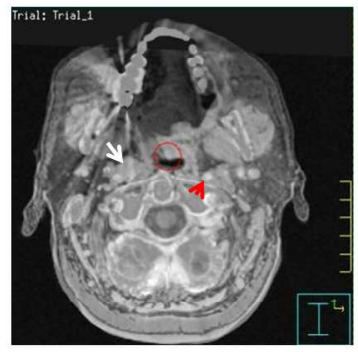

c

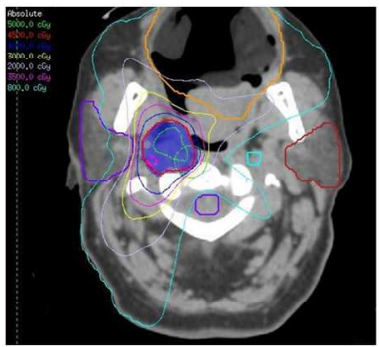

Figure 1. Treatment planning procedure for patients treated with HN-SBRT. (A) Representative axial slice of planning CT scan, $1 \mathrm{~mm}$ slice. The right RP tumor and carotid vessels are difficult to visualize. White arrow identifies the right RP tumor. Hollow red circle is isocenter. (B) Coregistration of the planning CT scan with a volume MRI in treatment immobilization position. Visualization of the tumor (white arrow) and contralateral carotid vessel (red arrow). Hollow red circle is isocenter. (C) Final HN-SBRT treatment plan with isodose lines. Right carotid artery (outlined in light blue) is receiving $<8 \mathrm{~Gy}$.

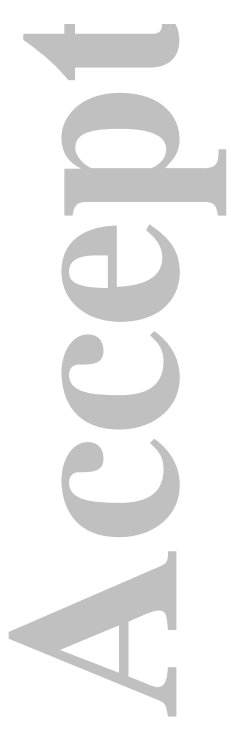

$254 \times 142 \mathrm{~mm}(300 \times 300 \mathrm{DPI})$

John Wiley \& Sons, Inc.

This article is protected by copyright. All rights reserved. 
A

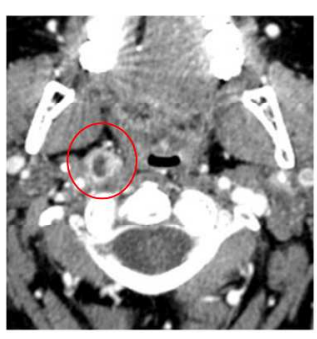

B

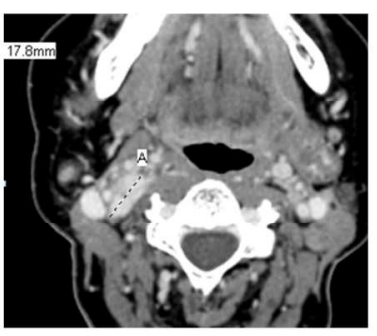

C

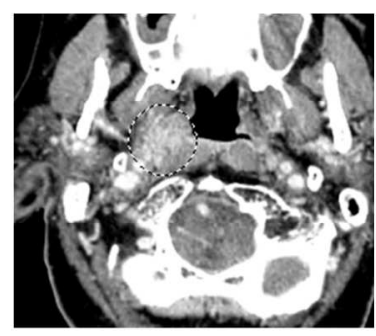

Figure 2. Patterns of disease presentation of patients included in analysis. (A) Isolated right retropharyngeal node metastasis, red circle. (B) Retropharyngeal node metastasis with extension to the ipsilateral carotid space and level 2A, dashed line. (C) Retropharyngeal node metastasis with extension to the ipsilateral nasopharynx, dashed circle.

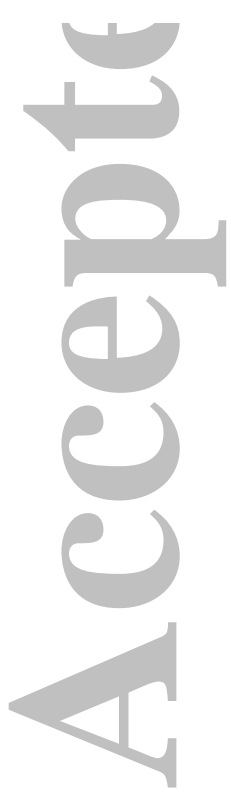

$254 \times 142 \mathrm{~mm}(300 \times 300$ DPI $)$

John Wiley \& Sons, Inc.

This article is protected by copyright. All rights reserved. 

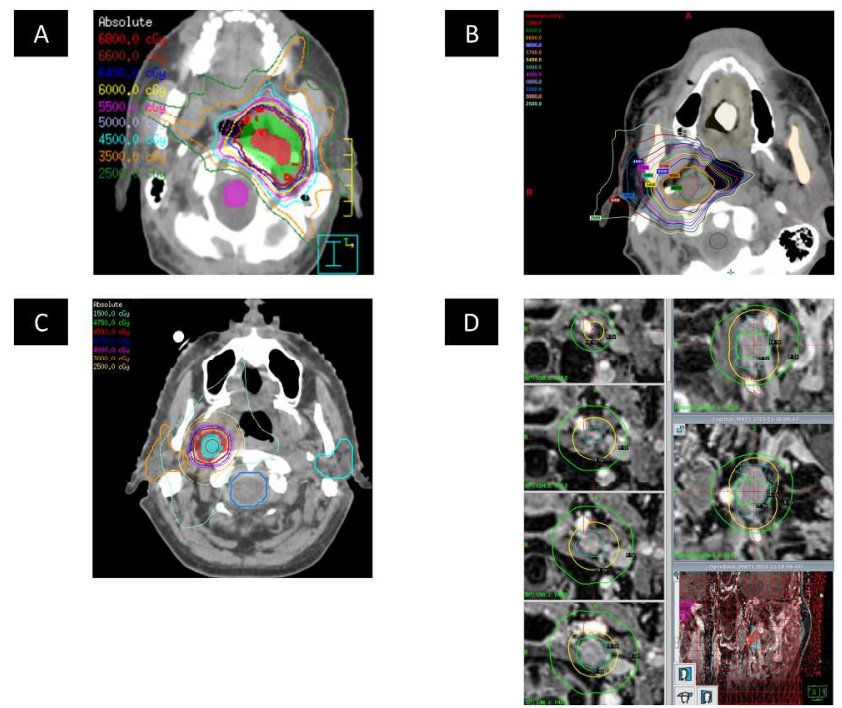

Figure 3. Radiation treatment plan representative images. (A) IMRT plan. (B) PBT plan. (C) HN-SBRT plan. (D) GK-SRS plan.

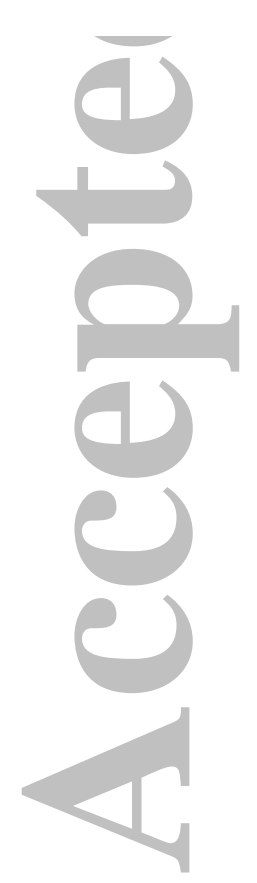

$254 \times 142 \mathrm{~mm}(300 \times 300$ DPI $)$

John Wiley \& Sons, Inc.

This article is protected by copyright. All rights reserved. 
A

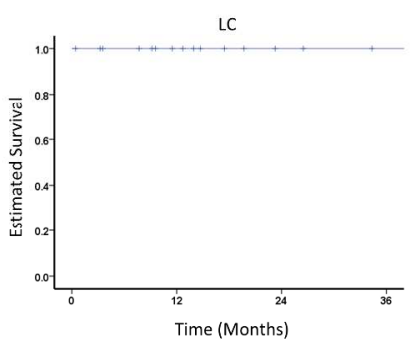

C

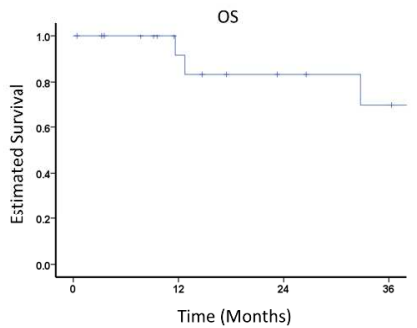

B

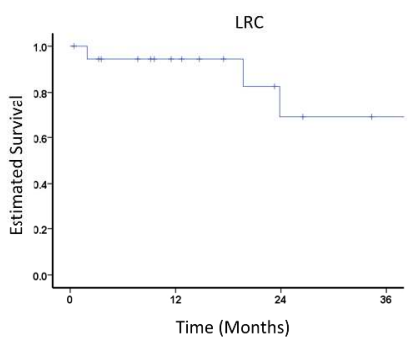

D

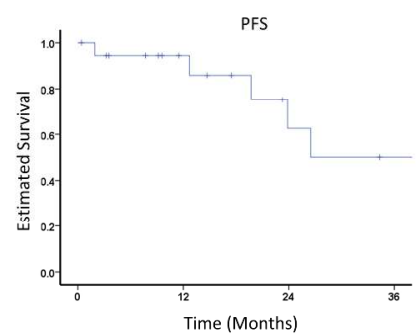

Figure 4. Clinical outcomes. (A) Local control (LC) for entire patient cohort $(n=19)$. (B) Locoregional control (LRC) for entire patient cohort $(n=19)$. (C) Progression free survival (PFS) for entire patient cohort $(n=$ 19). (D) Overall Survival (OS) for entire patient cohort $(n=19)$.

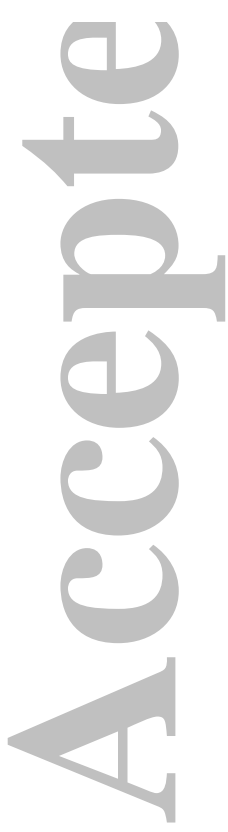

$254 \times 142 \mathrm{~mm}(300 \times 300$ DPI $)$

John Wiley \& Sons, Inc.

This article is protected by copyright. All rights reserved. 


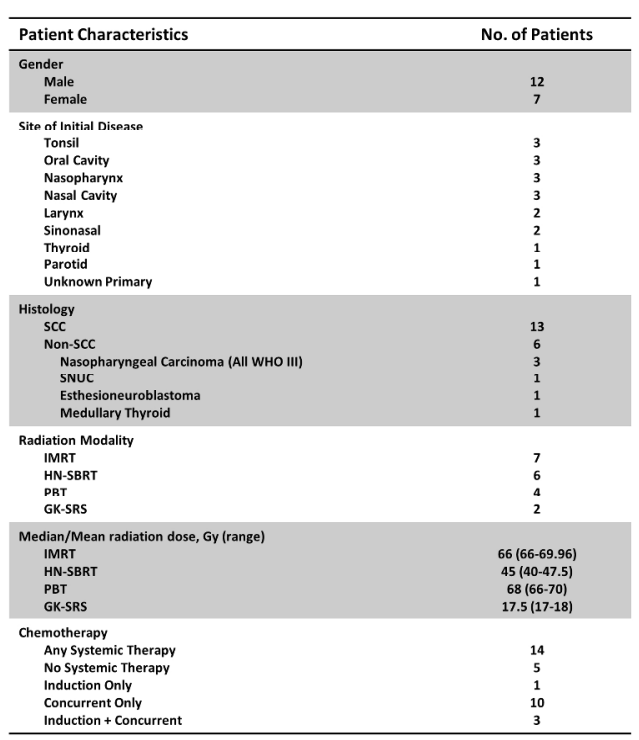

$254 \times 142 \mathrm{~mm}(300 \times 300$ DPI $)$

John Wiley \& Sons, Inc.

This article is protected by copyright. All rights reserved. 


\begin{tabular}{|c|c|c|c|c|c|}
\hline Treatment Related Toxicity & $\begin{array}{l}\text { No. of All } \\
\text { Adverse } \\
\text { Events }\end{array}$ & $\begin{array}{l}\text { No. of IMRT } \\
\text { Adverse } \\
\text { Events }\end{array}$ & $\begin{array}{l}\text { No. of PBT } \\
\text { Adverse } \\
\text { Events }\end{array}$ & $\begin{array}{l}\text { No. of HN- } \\
\text { SBRT } \\
\text { Adverse } \\
\text { Events }\end{array}$ & $\begin{array}{l}\text { No. of GK- } \\
\text { SRS } \\
\text { Adverse } \\
\text { Events }\end{array}$ \\
\hline Total & 35 & 18 & 5 & 10 & 2 \\
\hline $\begin{array}{l}\text { Acute } \\
\text { Late }\end{array}$ & $\begin{array}{c}28 \\
7\end{array}$ & $\begin{array}{c}15 \\
3\end{array}$ & $\begin{array}{l}4 \\
1\end{array}$ & $\begin{array}{l}9 \\
1\end{array}$ & $\begin{array}{l}0 \\
2\end{array}$ \\
\hline $\begin{array}{l}\text { Acute Toxicity Grade } \\
<3 \\
\geq 3\end{array}$ & $\begin{array}{l}25 \\
3\end{array}$ & $\begin{array}{l}12 \\
3\end{array}$ & $\begin{array}{l}4 \\
0\end{array}$ & $\begin{array}{l}9 \\
0\end{array}$ & $\begin{array}{l}0 \\
0\end{array}$ \\
\hline $\begin{array}{l}\text { Acute Grade } 3 \text { Toxicity Type } \\
\text { Mucositis } \\
\text { Other }\end{array}$ & $\begin{array}{l}3 \\
0\end{array}$ & $\begin{array}{l}3 \\
0\end{array}$ & $\begin{array}{l}\text { NA } \\
\text { NA }\end{array}$ & $\begin{array}{l}\mathrm{NA} \\
\mathrm{NA}\end{array}$ & $\begin{array}{l}\text { NA } \\
\text { NA }\end{array}$ \\
\hline $\begin{array}{l}\text { Acute Grade } 3 \text { Toxicity by Modality } \\
\text { IMKI } \\
\text { HN-SBRT/PBT/GK-SRS }\end{array}$ & s & NA & NA & NA & NA \\
\hline $\begin{array}{l}\text { Acute Grade }<3 \text { Toxicity Type } \\
\text { Mucositis } \\
\text { Dysphagia } \\
\text { Odynophagia } \\
\text { Xerostomia } \\
\text { Pain } \\
\text { Dermatitis } \\
\text { Weight Loss }\end{array}$ & $\begin{array}{l}4 \\
3 \\
3 \\
5 \\
3 \\
6 \\
1\end{array}$ & $\begin{array}{l}2 \\
3 \\
0 \\
1 \\
2 \\
3 \\
1\end{array}$ & $\begin{array}{l}0 \\
0 \\
0 \\
1 \\
1 \\
2 \\
0\end{array}$ & $\begin{array}{l}2 \\
0 \\
3 \\
3 \\
0 \\
0 \\
1 \\
0\end{array}$ & $\begin{array}{l}0 \\
0 \\
0 \\
0 \\
0 \\
0 \\
0\end{array}$ \\
\hline $\begin{array}{l}\text { Late Toxicity Grade } \\
\quad<3 \\
\geq 3\end{array}$ & $\begin{array}{l}7 \\
0\end{array}$ & $\begin{array}{l}3 \\
0\end{array}$ & $\begin{array}{l}1 \\
0\end{array}$ & $\begin{array}{l}1 \\
0\end{array}$ & $\begin{array}{l}2 \\
0\end{array}$ \\
\hline $\begin{array}{l}\text { Late Grade <3 Toxicity Type } \\
\text { Xerostomia } \\
\text { Trismus } \\
\text { Temporal Lobe Necrosis }\end{array}$ & $\begin{array}{l}5 \\
1 \\
1\end{array}$ & $\begin{array}{l}2 \\
0 \\
1\end{array}$ & $\begin{array}{l}0 \\
1 \\
0\end{array}$ & $\begin{array}{l}1 \\
0 \\
0\end{array}$ & $\begin{array}{l}2 \\
0 \\
0\end{array}$ \\
\hline
\end{tabular}

$254 \times 142 \mathrm{~mm}(300 \times 300 \mathrm{DPI})$

John Wiley \& Sons, Inc.

This article is protected by copyright. All rights reserved. 


\section{University Library}

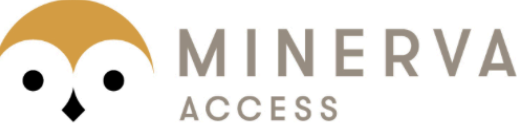

A gateway to Melbourne's research publications

Minerva Access is the Institutional Repository of The University of Melbourne

Author/s:

Pollard, C;Nguyen, TP;Ng, SP;Frank, SJ;Garden, AS;Gunn, GB;Fuller, CD;Beadle, BM;Morrison, WH;Shah, SJ;Wang, H;Tung, S;Wang, C;Ginsberg, LD;Zafereo, ME;Sturgis, EM;Su, SY;Hanna, EY;Rosenthal, DI;Phan, J

Title:

Clinical outcomes after local field conformal reirradiation of patients with retropharyngeal nodal metastasis

Date:

2017-10-01

Citation:

Pollard, C., Nguyen, T. P., Ng, S. P., Frank, S. J., Garden, A. S., Gunn, G. B., Fuller, C. D., Beadle, B. M., Morrison, W. H., Shah, S. J., Wang, H., Tung, S., Wang, C., Ginsberg, L. D., Zafereo, M. E., Sturgis, E. M., Su, S. Y., Hanna, E. Y., Rosenthal, D. I. \& Phan, J. (2017). Clinical outcomes after local field conformal reirradiation of patients with retropharyngeal nodal metastasis. HEAD AND NECK-JOURNAL FOR THE SCIENCES AND SPECIALTIES OF THE HEAD AND NECK, 39 (10), pp.2079-2087. https://doi.org/10.1002/hed.24872.

Persistent Link:

http://hdl.handle.net/11343/293218 